\title{
A Novel Method for Starting of VSC-HVDC System
}

\author{
Guntamukkala Vamsi, P Kiran Kumar, G Joga Rao
}

\begin{abstract}
The voltage source converters (VSCs) are the circuits, which convert the power from one form to the other. The application of voltage source converter is vital in HVDC systems. The voltage source converter technology is employed for the smooth operation of any HVDC system. Hence, the HVDC systems based on VSC are gaining importance compared to the other HVDC systems. The starting up process of HVDC system is associated with large value of current, so a proper method of starting is required for the safe operation of the HVDC system. In this paper, a new and novel method is proposed for the smooth starting of the VSC based HVDC system, which will limit the current successfully with high speed operation. Index Terms: Nine level MLI, Control of inverter, Modular Inverter.
\end{abstract}

Key Words: THD, Optimum Angles, Iterative Methods.

\section{INTRODUCTION}

All world are moving towards the electricity that is generated by the nonconventional energy sources. Various sources of energy are photovoltaic, wind, gas based, and tidal energy. As on today India is in third position in the electrical energy consumption. To collect the energy produced in the plants, EHVAC, and the HVDC can be used. Due to the less losses in HVDC transmission, it is preferable in electric power transmission. The investment required for HVDC is also less compared to EHVAC. There are several HDC projects that are already in use for the transmission of electric power in India. The amount of power that is transmitted varies from $1000 \mathrm{MW}$ to $3000 \mathrm{MW}$. The break even distance in HVDC is high compared to the EHVAC, which is the attracting feature of HVDC transmission system. HVDC systems can be implemented using two links or multiple links. There are several challenges in implementation of multiple link HVDC system compared to two link systems.

The HVDC systems are initiated first time in the year of 1897 by inventing the low voltage DC supply for very short distance. The development of mercury arc rectifier technology in power electronics made the easy conversion of power from AC to DC.

Manuscript received on May 26, 2021.

Revised Manuscript received on July 26, 2021.

Manuscript published on 30 July, 2021.

* Correspondence Author

Mr. G.Vamsi*, M.Tech, Department of Power Electronics, Raghu Institute of Technology (Autonomous), Visakhapatnam (Andhra Pradesh), India.

Mr. P.Kiran Kumar, Assistant Professor, Department of EEE, Raghu Institute of Technology (Autonomous), Visakhapatnam (Andhra Pradesh), India.

Dr. G Joga Rao, Associate Professor, Department of EEE, Raghu Institute of Technology (Autonomous) Visakhapatnam (Andhra Pradesh), India.

(C) The Authors. Published by Blue Eyes Intelligence Engineering and Sciences Publication (BEIESP). This is an open access article under the CC BY-NC-ND license (http://creativecommons.org/licenses/by-nc-nd/4.0/)

The advancements in power conversion are made simpler due to the advanced technologies. The HVDC consists of two ends, the sending end and the receiving end. The sending end converter requires $\mathrm{AC}$ to $\mathrm{DC}$ conversion and the receiving end require $\mathrm{DC}$ to $\mathrm{AC}$ conversion. The power conversion process at each end requires converter to be installed. After conversion of power from AC to DC, the transmission will takes place. The transmission requires only two conductors using HVDC transmission.

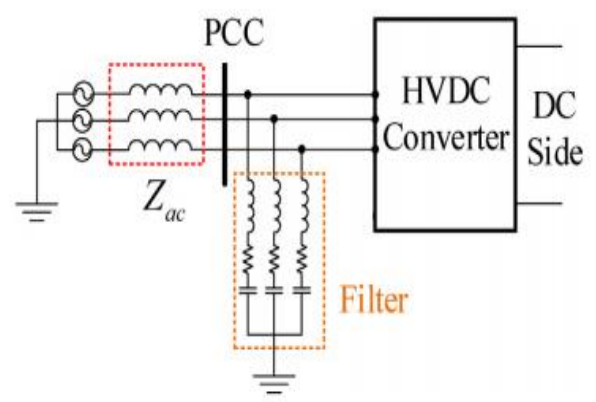

Figure 1 HVDC System.

The continuous monitoring of the various voltages and the various power flows are very vital in the performance analysis of HVDC systems. Especially with the inclusion of voltage source converter, the changes that occur in power flows and voltages needs to be examined carefully. In order to analyze the system, it requires the modeling of the system and related converters. The modeling process involved the mathematical equations relating to the system under study and various constraints to be imposed during the control of the power.

Any system suffers from many operation and control issues. We have various issues related to the VSC HVDC system. The aspects related to the system under study are related to operation, control, power flow, stability, and converter topology, control strategy of converter, and power and voltages at various ends. The following are the various possible works related to the HVDC systems.

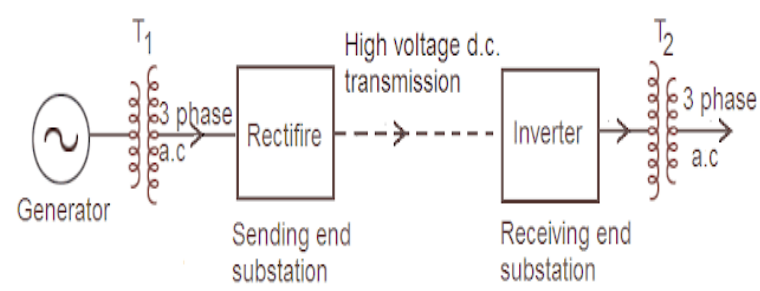

Figure 2 HVDC Block diagram.

Published By:

Blue Eyes Intelligence Engineering and Sciences Publication

(C) Copyright: All rights reserved.

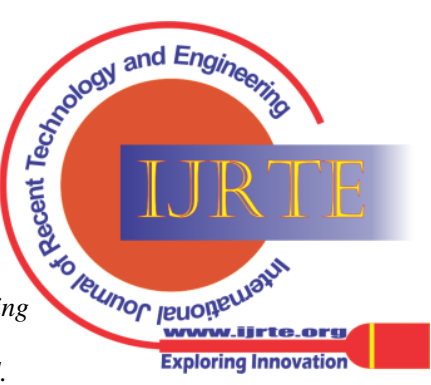


- The modelling of two terminals system.

- Analysis of HVDC system in SIMULINK.

- Starting current issues.

- Study of voltages at various ends.

- $\quad$ Study of real and reactive power flows.

In this paper, the attentions is shown towards the limiting the magnitude of starting current during the starting of the VSC HVDC systems. The new starting control circuit is proposed to limit the starting current and the simulation related to the same are presented.

\section{OVER CURRENT IN HVDC SYSTEM}

Electrical power is generated in remote areas. Usually they are located very far from the load centers. Due the longer distance between the generating centers and the load centers, the transmission of the electrical power becomes complex, and it requires very large, costly power transmission system. So, the transmission of power in bulk amount for the longer distances is the challenging task for the electrical transmission engineers. The most important technologies that are used for this purpose are EHVAC and HVDC transmission systems.

The power transmission system should be simple in construction, cost effective, and more importantly it should provide better control of power. The HVDC power transmission technology fulfilling all the requirements of the effective transmission system. The main advantage of HVDC is the power flow direction depends on the magnitude of the voltage, where as in case of EHVAC phase angle also required. To provide flexibility in control HVDC is used with a power electronic converter. Usually voltage source converters are most prominent and suitable with the HVDC applications.

One of the most severe issues related to the operation of the system is the control of over currents that are produced during the starting of the system.

\subsection{Overcurrent in HVDC}

A two level inverter based HVDC system is considered in this analysis. It consists of all the equipment like converter stations, power factor arrangement systems, and filters etc.

The structure of two level HVDC is shown in Figure 3. If $x$ is the reactance between two ends, and the $f$ is the frequency of the system, then from the HVDC link we can get

$$
\left\{\begin{array}{l}
P=-\frac{U_{\mathrm{s}} U_{\mathrm{c}}}{X} \sin \delta \\
Q=-\frac{U_{\mathrm{s}}\left(U_{\mathrm{s}}-U_{c} \cos \delta\right)}{X}
\end{array}\right.
$$

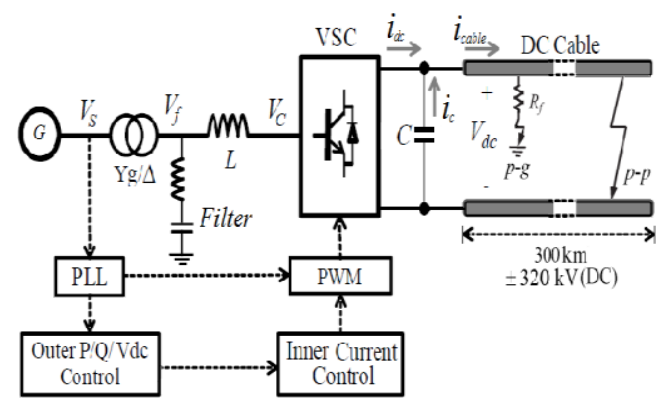

Figure 3 HVDC With two level Inverter.
The above system variables can be expressed in Matrix form as

$$
L \frac{\mathrm{d}}{\mathrm{d} t}\left[\begin{array}{l}
i_{d} \\
i_{q}
\end{array}\right]=\left[\begin{array}{l}
u_{\mathrm{s} d} \\
u_{\mathrm{s} q}
\end{array}\right]-R\left[\begin{array}{l}
i_{d} \\
i_{q}
\end{array}\right]-\omega L\left[\begin{array}{c}
+i_{q} \\
-i_{d}
\end{array}\right]-\left[\begin{array}{l}
u_{\mathrm{c} d} \\
u_{\mathrm{c} q}
\end{array}\right]
$$

The figure below shows the equivalent circuit of the HVDC system for the system under study.

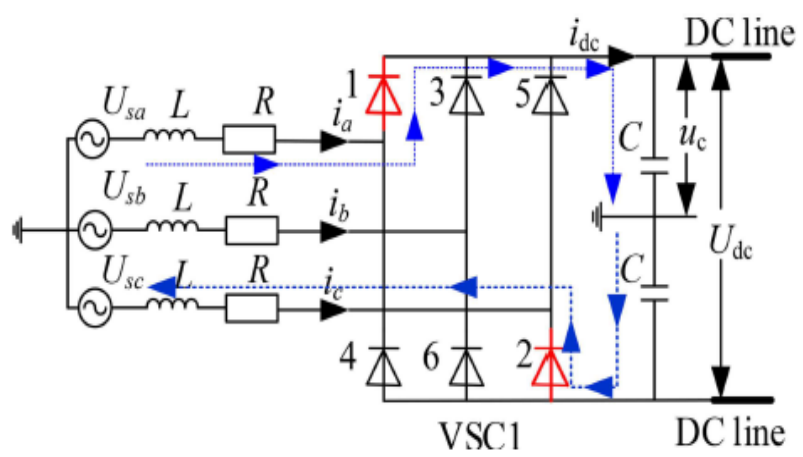

Figure 4 Equivalent circuit.

From the analysis of the above system and its equivalent circuit we get following expressions, which will give the magnitude of the currents that are produced during the starting.

$$
\begin{aligned}
& L C \frac{\mathrm{d}^{2} u_{c}}{\mathrm{~d} t^{2}}+R C \frac{\mathrm{d} u_{c}}{\mathrm{~d} t}+u_{c}=U_{s a} \\
& L C \frac{\mathrm{d}^{2} u_{c}}{\mathrm{~d} t^{2}}+R C \frac{\mathrm{d} u_{c}}{\mathrm{~d} t}+u_{c}=U_{s m} \\
& \left\{\begin{array}{l}
i_{d c}=\sqrt{\frac{4 C}{4 L-R^{2} C}} U_{\mathrm{sm}} \mathrm{e}^{-t / \tau} \sin \omega t \\
u_{c}=U_{\mathrm{sm}}\left[1-\sqrt{\frac{4 C}{4 L-R^{2} C}} \mathrm{e}^{-t / \tau} \cos (\omega t+\varphi)\right] \\
\left\{\begin{array}{l}
\lambda_{1,2}=-\alpha \pm \mathrm{j} \omega=-\frac{R}{2 L} \pm \mathrm{j} \sqrt{\frac{1}{L C}-\left(\frac{R}{2 L}\right)^{2}} \\
\varphi=\arctan \frac{\alpha}{\omega} \quad \tau=\frac{2 L}{R}
\end{array}\right.
\end{array}\right.
\end{aligned}
$$

The above equations give the magnitudes of currents that occur during the starting of HVDC system shown in figure 3. It is difficult to control those currents without any auxiliary circuit.

In order to test these currents, a practical system is considered for the analysis, the specifications of which are shown in the table below.
Published By:

Blue Eyes Intelligence Engineering and Sciences Publication (C) Copyright: All rights reserved.

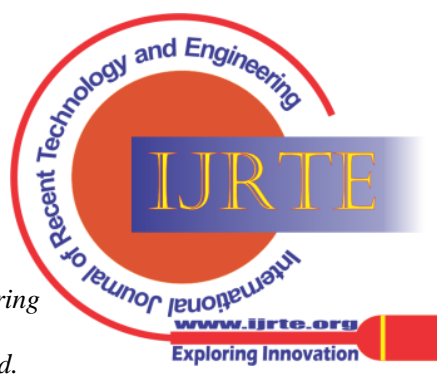


Table I Operating parameters.

\begin{tabular}{lc}
\hline Parameters & Rated value \\
\hline phase reactance & $L=10 \mathrm{mH}$ \\
current limiting inductor & $L_{1}=10 \mathrm{mH}$ \\
phase resistance & $R=0.314 \Omega$ \\
$D C$ capacitor & $C=500 \mu \mathrm{F}$ \\
transformer ratio & $110 / 10 \mathrm{kV}$ \\
$D C$ voltage & $U_{\text {dcref }}=20 \mathrm{kV}$ \\
rated active power & $P_{\text {ref }}=5 \mathrm{MW}$ \\
rated reactive power & $Q_{\text {ref }}=2 \mathrm{MVar}$ \\
$t_{1}, t_{2}$ & $0.1,1$ \\
$t_{3}, t_{4}$ & $1.5,2$ \\
\hline
\end{tabular}

The mono polar link utilizes only one conductor, where as ground will act like a second conductor for it. The unidirectional power flow is possible with mono polar link. In case of bi polar link power can be transmitted in both the direction, which is not possible with mono polar link. The multi terminal links, more number of links are available, which is used for the interconnection of various sub system. The complexity of control increases with increase in number of links in case of homo polar link.
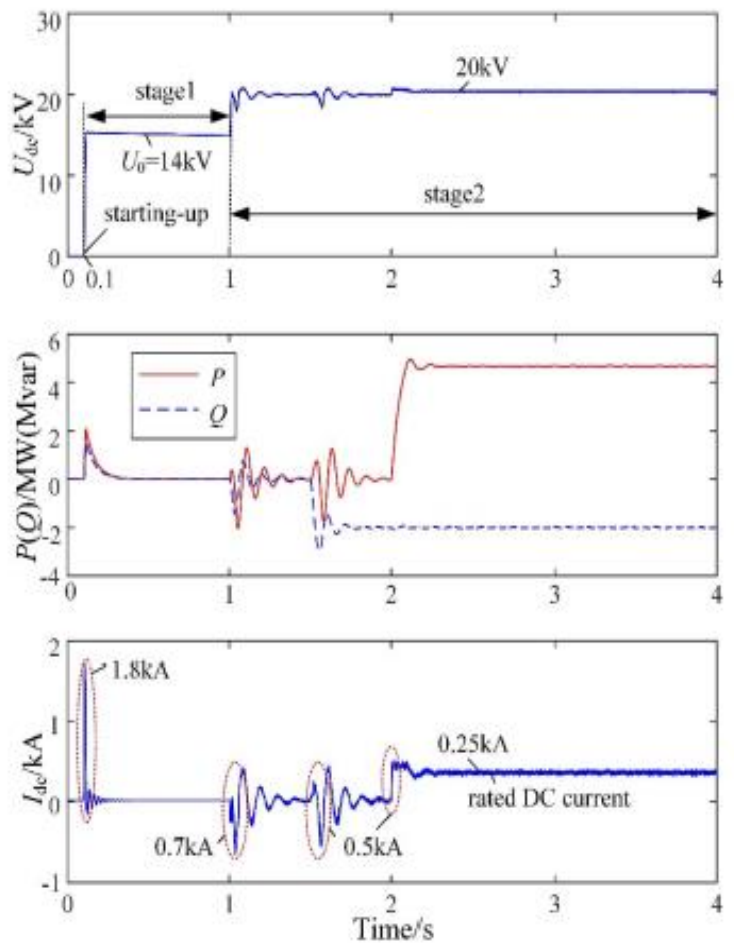

Figure 5 wave forms during starting.

Hence, from the above wave forms it is clear that the current limiting circuit is necessary for the successful operation of the HVDC system.

\section{STARTING CIRCUIT DESIGN}

In this section, the design of the newly proposed starting circuit for the two level inverter based HVDC system presented in previous section. The current expression is derived and the plots are also shown.

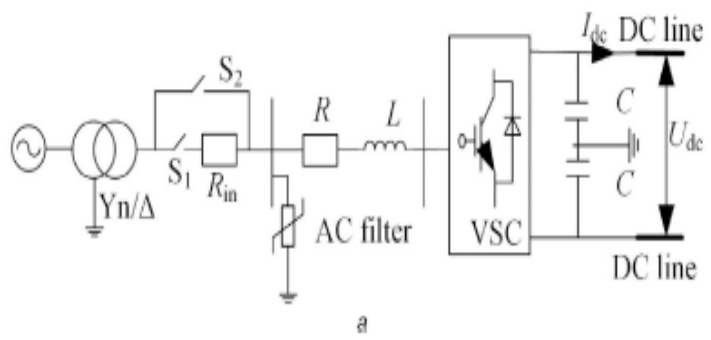

Figure 6 Starting circuit of HVDC

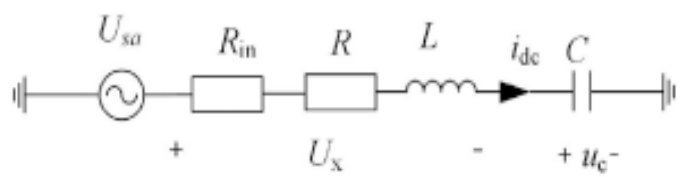

Figure 6 Equivalent Circuit of Starting Circuit.

Following is the method to derive the current expression after adding the control circuit in the existing system.

$$
\begin{aligned}
& L C \frac{\mathrm{d}^{2} u_{c}}{\mathrm{~d} t^{2}}+R_{1} C \frac{\mathrm{d} u_{c}}{\mathrm{~d} t}+u_{c}=U_{\mathrm{sm}} \\
& \left\{\begin{array}{l}
i_{d c}=\sqrt{\frac{4 C}{4 L-R_{1}^{2} C}} U_{\mathrm{sm}} \mathrm{e}^{-t / \tau} \sin \omega t \\
u_{c}=U_{\mathrm{sm}}\left[1-\sqrt{\frac{4 C}{4 L-R_{1}^{2} C}} \mathrm{e}^{-t / \tau} \cos (\omega t+\varphi)\right]
\end{array}\right.
\end{aligned}
$$

Where,

$$
\begin{gathered}
\varphi=\arctan \frac{\alpha}{\omega} \quad \lambda_{1,2}=-\alpha \pm \mathrm{j} \omega= \\
-\frac{R_{1}}{2 L} \pm \mathrm{j} \sqrt{\frac{1}{L C}-\left(\frac{R_{1}}{2 L}\right)^{2}} \\
\left\{\begin{array}{l}
i_{\mathrm{dc}}=\frac{U_{\mathrm{sm}}}{L} t \mathrm{e}^{-t / \tau} \\
u_{\mathrm{c}}=U_{\mathrm{sm}}\left[1-\left(1+\frac{t}{\tau}\right) \mathrm{e}^{-t / \tau}\right]
\end{array}\right.
\end{gathered}
$$

Where,

$$
\lambda_{1,2}=-\alpha=-\frac{R_{1}}{2 L}
$$

$$
\left\{\begin{array}{l}
i_{\mathrm{dc}}=\sqrt{\frac{4 C}{R_{1}^{2} C-4 L}} U_{\mathrm{sm}} \mathrm{e}^{-t / \tau} \operatorname{sh} \beta t \\
u_{\mathrm{c}}=U_{\mathrm{sm}}\left[1-\sqrt{\frac{4 C}{R_{1}^{2} C-4 L}} \mathrm{e}^{-t / \tau} \operatorname{sh}(\beta t+\varphi)\right]
\end{array}\right.
$$

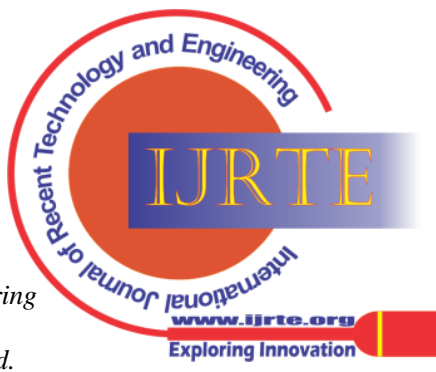


Where,

$$
\begin{aligned}
& \varphi=\arctan \frac{\alpha}{\beta} \quad \lambda_{1,2}=-\alpha \pm \beta= \\
& -\frac{R_{1}}{2 L} \pm \sqrt{\left(\frac{R_{1}}{2 L}\right)^{2}-\frac{1}{L C}}
\end{aligned}
$$

The maximum value of the current is obtained using following equations.

$$
\begin{aligned}
& t_{\max }=\frac{\ln \lambda_{2}-\ln \lambda_{1}}{\lambda_{1}-\lambda_{2}} \\
& i_{d c \max }=\sqrt{\frac{4 C}{R_{1}^{2} C-4 L}} U_{\mathrm{sm}} \mathrm{e}^{-t_{\max } / \tau} \operatorname{sh} \beta t_{\max }
\end{aligned}
$$

And the condition to achieve the minimum current is

$$
i_{\max } \sqrt{R_{1}^{2}+(\omega L)^{2}} \geq U_{\max }
$$

The power expressions are given by

$$
\begin{aligned}
k_{1} & =\frac{\Delta P_{\max }}{\Delta U_{d c \max }} \\
\Delta U_{d c} & =U_{d c r e f}-U_{d c} \\
\Delta U_{d c \max } & =U_{d c \max }-U_{d c r e f} \\
& =U_{d c r e f}-U_{d c m i n}
\end{aligned}
$$

From the equation (10), and (12), it is sure that the current is minimum with usage of the control circuit in HVDC system. The initial current magnitude decreased drastically by employing the proposed control circuit at the beginning of the circuit.

The following are the control circuits that are required for the control of those variables.
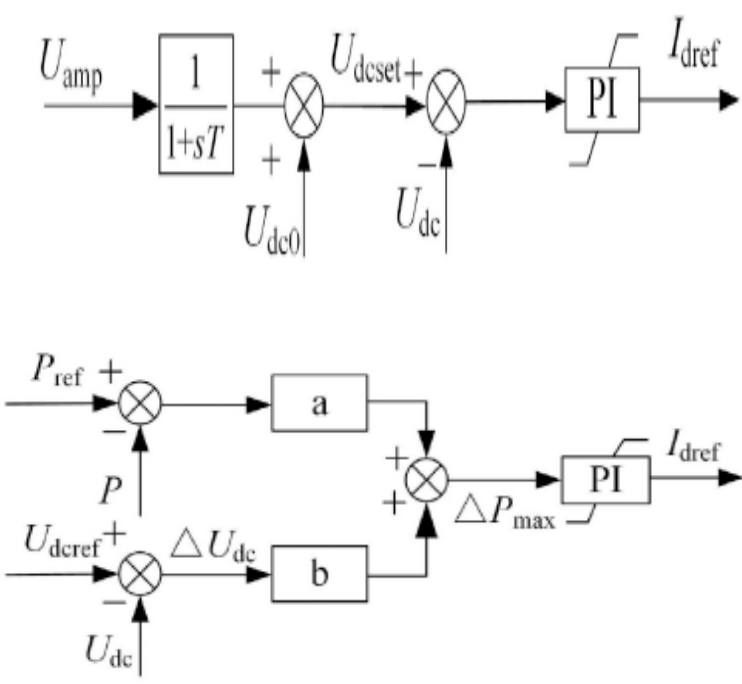

Retrieval Number: 100.1/ijrte.B60090710221

DOI: 10.35940/ijrte.B6009.0710221

Journal Website: www.ijrte.org
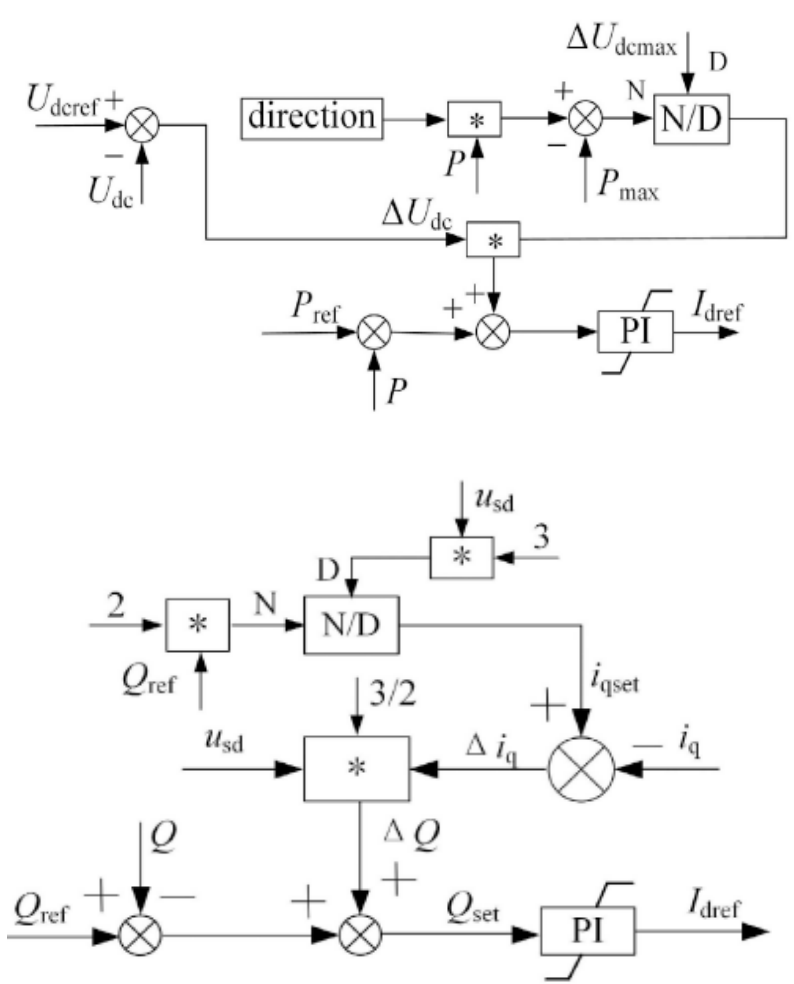

Figure 7 various control circuits.

By using the above control circuits, it is possible to achieve the low starting current, which is effective in achieving the smooth control of the entire system.

$$
\begin{gathered}
i_{q s e t}=\frac{2 Q_{r e f}}{3 u_{s d}} \\
\Delta i_{q}=i_{q s e t}-i_{q} \\
\Delta Q=\frac{3}{2} u_{s d} \Delta i_{q} \\
Q_{s e t}=Q_{r e f}-Q+\frac{3}{2} u_{s d} \Delta i_{q}
\end{gathered}
$$

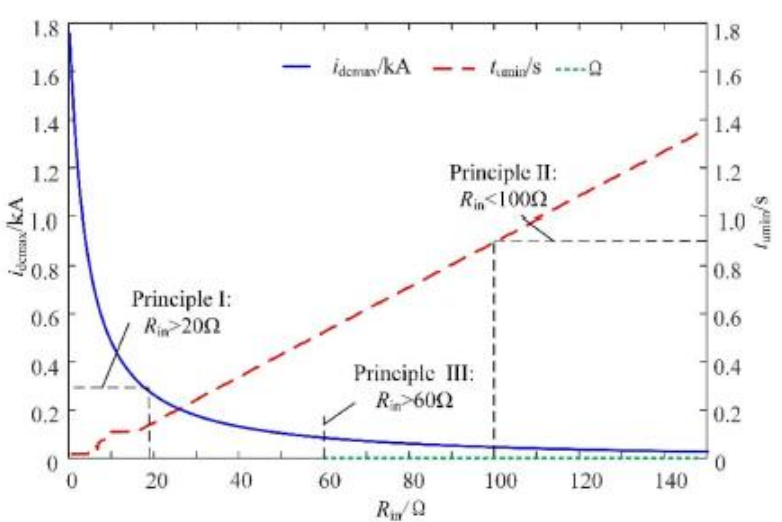

Figure 8 various parameters of the circuits.

Published By:

Blue Eyes Intelligence Engineering

and Sciences Publication

(C) Copyright: All rights reserved.

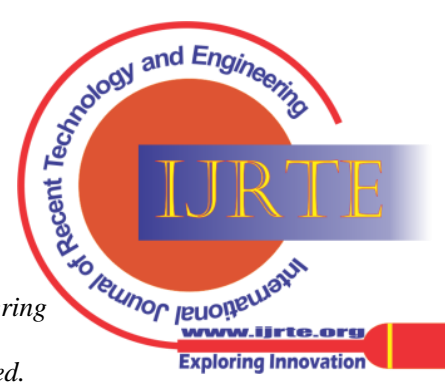


The change or variation in the current and power and other parameter values is expressed in previous equations. Through the equations, the variation can be calculated.

\section{SIMULATION RESULTS}

To verify the fast starting with the limited current, the simulations are carried out for the test system and the values and graphs for various parameters is obtained and shown in this section. All the simulations of the test system are carryout in PSCAD software, which is exclusively for the study and analysis of the power system related domains.
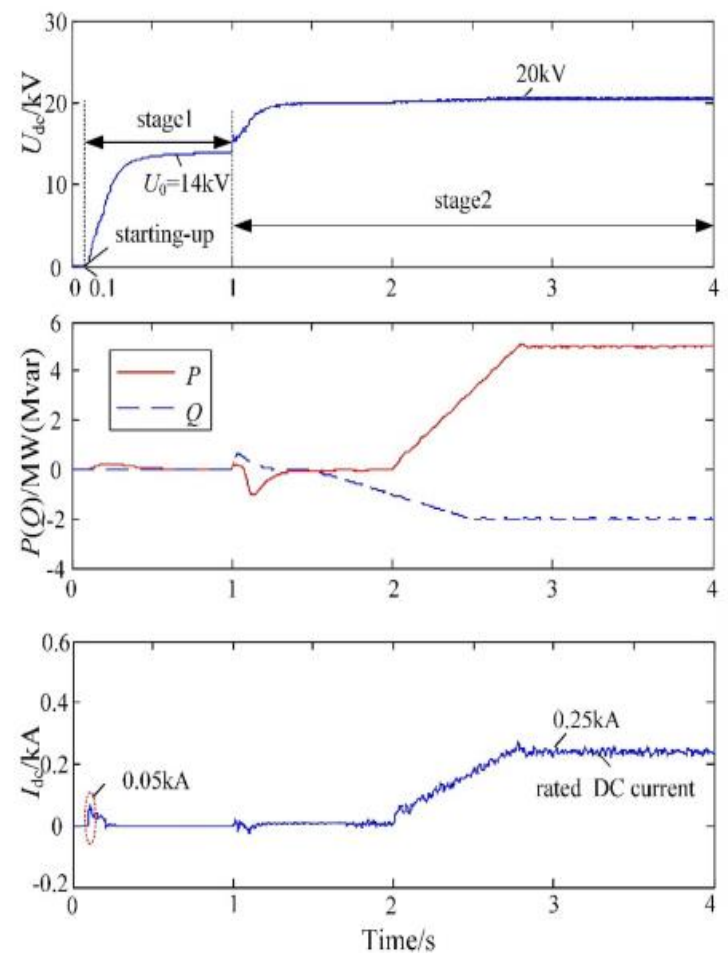

Figure 9 Voltage, power, and Current.
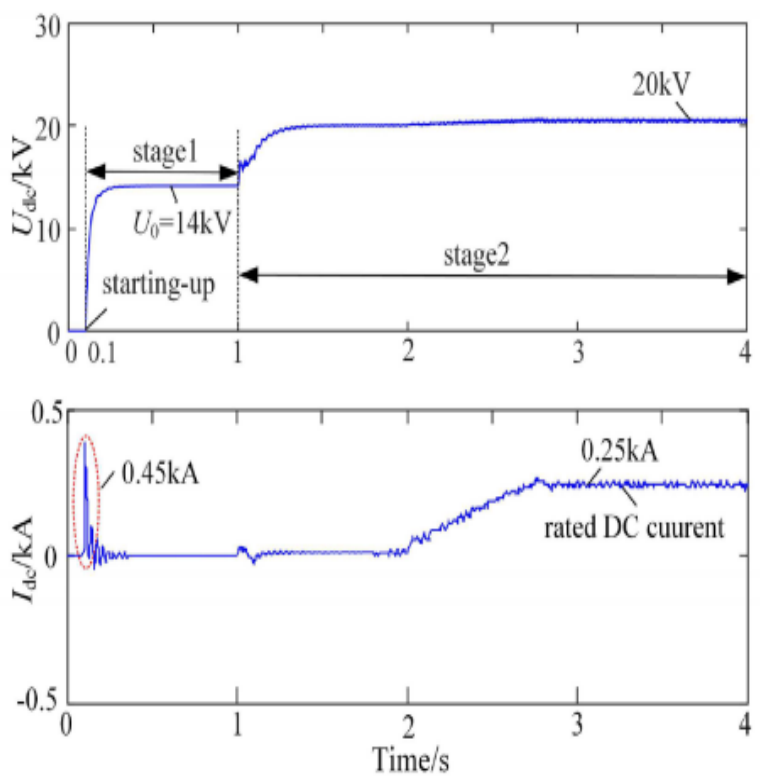

FIGURE 10 Changes In Current And Voltage.
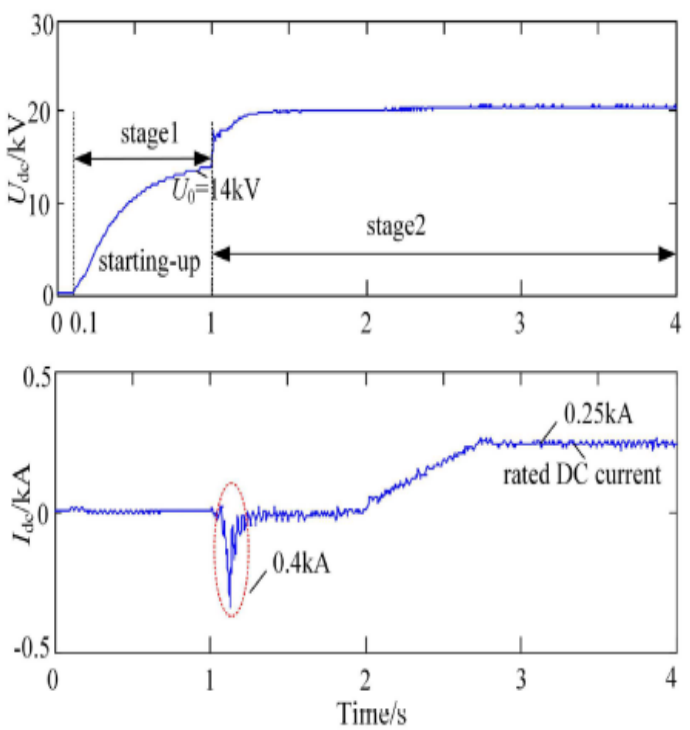

Figure 11 Load Voltage for various Resistance.

From the simulation results, it is clear that the current during starting of the system is reduced with the starting circuit when compared the system without ant starting circuit.

Table II Values of various parameters.

\begin{tabular}{lcc}
\hline Control types & Parameters & Value \\
\hline DC voltage slope control & $T$ & $0.067 \mathrm{~s}$ \\
& $k$ & $30 \mathrm{kV} / \mathrm{s}$ \\
active power adaptive droop controller & $\Delta U_{\text {dcmax }}$ & $1 \mathrm{kV}$ \\
& $P_{\max }$ & $6 \mathrm{MW}$ \\
reactive power deviation controller & $i_{\text {qset }}$ & $0.133 \mathrm{kA}$ \\
\hline
\end{tabular}

\section{CONCLUSION}

The performance of the auxiliary starting circuit is proposed and analyzed. The new starting circuit which is more suitable for the VSC HVDC system is operated and simulation results are obtained using PSCAD software. The results clarifies that the usage of the new circuit limits the starting current to a very low value which is well below the rated value. Hence, this work suggests for the usage of the starting circuit for good operation of the HVDC system with voltage source converters.

\section{REFERENCES}

1. Haileselassie, T. M. (2012). Control, dynamics and operation of multi-terminal VSC-HVDC transmission systems.

2. Liang, H., Li, G., Li, G., Li, P., \& Yin, M. (2005, August). Analysis and design of $\mathrm{H} \infty$ controller in VSC HVDC systems. In 2005 IEEE/PES Transmission \& Distribution Conference \& Exposition: Asia and Pacific (pp. 1-6). IEEE.

3. Wu, G., Liang, J., Zhou, X., Li, Y., Egea-Alvarez, A., Li, G., ... \& Zhang, X. (2017). Analysis and design of vector control for VSCHVDC connected to weak grids. CSEE Journal of Power and Energy Systems, 3(2), 115-124.

4. Chao, Z., Xiaoxin, Z., \& Ruomei, L. (2006, October). Dynamic modeling and transient simulation for VSC based HVDC in multimachine system. In 2006 International Conference on Power System Technology (pp. 1-7). IEEE.

Blue Eyes Intelligence Engineering

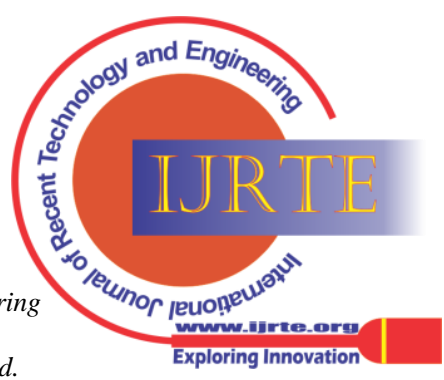


5. Zeng, Dan, Jianguo Yao, Shengchun Yang, Ke Wang, and Yaping Li. "Economy comparison of VSC-HVDC with different voltage levels." Automation of Electric Power Systems 35, no. 20 (2011): 98102

6. Bathurst, G., \& Bordignan, P. (2015, February). Delivery of the Nan'ao multi-terminal VSC-HVDC system. In 11th IET International Conference on AC and DC Power Transmission (pp. 16). IET.

7. Zeng, Dan, Jianguo Yao, Shengchun Yang, Ke Wang, and Yaping Li. "Economy comparison of VSC-HVDC with different voltage levels." Automation of Electric Power Systems 35, no. 20 (2011): 98102.

8. Yang, J., Zheng, J., Tang, G., \& He, Z. (2010, March). Characteristics and recovery performance of VSC-HVDC DC transmission line fault. In 2010 Asia-Pacific Power and Energy Engineering Conference (pp. 1-4). IEEE.

9. Liang, Jun, Oriol Gomis-Bellmunt, Janaka Ekanayake, and Nicholas Jenkins. "Control of multi-terminal VSC-HVDC transmission for offshore wind power." In 2009 13th European Conference on Power Electronics and Applications, pp. 1-10. IEEE, 2009.

10. Oates, C. (2014). Modular multilevel converter design for VSC HVDC applications. IEEE Journal of Emerging and Selected Topics in Power Electronics, 3(2), 505-515.

11. Chaudhary, Sanjay K., Remus Teodorescu, Pedro Rodriguez, Philip Carne Kjaer, and Ani M. Gole. "Negative sequence current control in wind power plants with VSC-HVDC connection." IEEE Transactions on Sustainable energy 3, no. 3 (2012): 535-544.

\section{AUTHORS PROFILE}

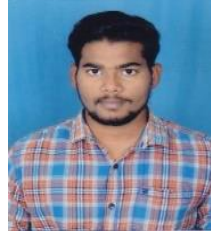

Mr. G. Vamsi, is pursuing M.Tech (Power electronics) in Raghu Institute of Technology (Autonomous) Visakhapatnam. He obtained B.Tech (Electrical and Electronics Engineering)

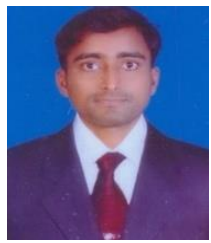

Mr. P. Kiran Kumar, is working as an assistant professor in the department of EEE, RAGHU INSTITUTE OF TECHNOLOGY (Autonomous). He obtained B.Tech (EEE) and M.Tech ( ENERGY SYSTEMS) DEGREE FROM JNTU HYDERABAD in 2008 and 2010 respectively. He has more than 9 years' experience in various Colleges and 5 publications. Area of interest machine learning. He is a life member of the Indian Society for Technical Education.

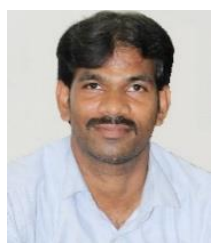

Dr. G Joga Rao, is working as an associate professor in the department of EEE, Raghu Institute of Technology (Autonomous) Visakhapatnam. He obtained B.Tech (Electrical Engineering) and M.Tech (Electrical Power Engineering) degree from J.N.T University, Hyderabad, in 2004 and 2007 respectively. He completed his doctoral program from S.R University, India in 2017. He has more than 15 years of teaching experience in various colleges and published more than 50 publications in various reputed international journals. His area of interest includes Energy Systems, Power Electronics and Renewable Energy Technologies. He is a life member of the Indian Society for Technical Education and Institute of Engineers IE.

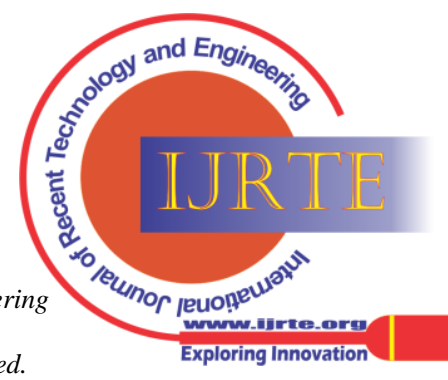

